\title{
Optimization of Ball Screw Diameter using Finite Element Method to Achieve Minimum Deflection
}

\author{
Rahul Thakur*, Varinder Mandley, Sashank Thapa \\ Department of Mechanical Engineering, \\ Green Hills Engineering College Solan, 173212, Himachal Pradesh, India \\ *trahul031@gmail.com
}

\begin{abstract}
Ball-Screw is a me chanical actuator that transforms the rotational motion of the motor into a linear motion of drive. The ball-screw is commonly used in industrial precision machines and due to this very reason it had been a common topic of rese arch for many scholars, as precision in motion renders to precision in work directly. In this paper, some of the work done by different research scholars on different parametric aspects of ball screw had been discussed alongside optimization of ball screw diame ter. The aspects which had been reviewed are elastic deformation \& stiffness in ball screw, feed velocity and preloading, preload control in ball screw and various other aspects of preloading such as loss detection. Furthermore, the Finite elemental method had been applied to find the suitable diameter of the ball screw to render minimum deflection and stress value possible with the chosen material.
\end{abstract}

Keywords: Ball-screw, Finite Element Method, Dynamic load, elastic deformation, stress, stiffness, multi-scale entropy.

\section{I.INTRODUCTION}

In modern machine tools deploying numeric controllers to move the tool as well as work concerning each other, ball screw had been a favorable means to convert and convey the motion from source to required end. Hence it also increas es the need of producing the more precise and hybrid design of the same with an elaborated design analysis to impart high precision on users' end. Various parts of the ball screw mechanism had been depicted inFigure 1 shown below.

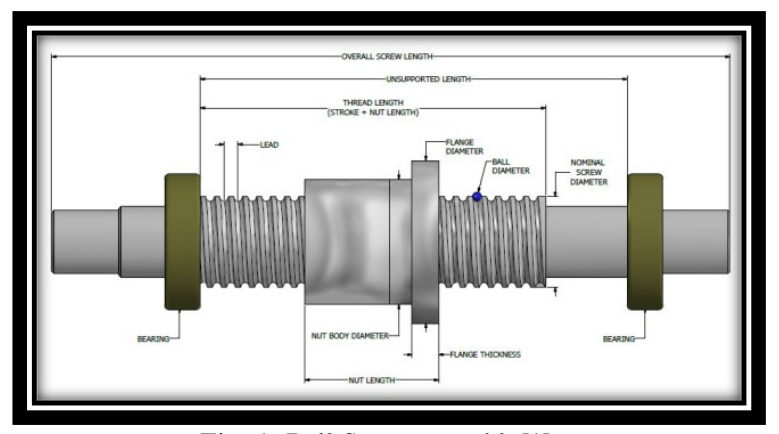

Fig. 1. Ball-Screw assembly[1]

[2] Zaehl et al. experimentally studied the Finite Element Model of the feed drive system of Ball-Screw. To grasp the feasible drive performance on machine tools they analyzed the dynamic behavior of the whole mechatronic system. The feed axis of a feed drives test station acted here as an example for the presentation of the feed drive modeling.

The author found that with the feed drive test station the whole machine frame along with drive structures can be figured in an integral FEM model by using MSC Nastran/MSC Patran FEM software and also vibration behavior of the whole mechanical system was analyzed.

[3] Kamalzadeh et al. experimentally investigated the robustcompensation of elastic deformation in ball-screw drives. They studied that the reason behind the occurrence of elastic deformation in ball-screw was internal forces, guideway friction and cutting forces. Due to this deformation, the expansion and compression occur in the ball-screw and there was a fall in the dynamic linear positioning robustness.

They developed a convenient automatic model to reduce the suicidal effect of elastic deformation. They introduced a closed-loop compensation method. It was found that by using this method the elastic deformation of the ball-screw drive was controlled. And this method is also effective for improving the deciding translational accuracy of ball-screw drive in the existence of high accelerations, cutting forces and load transformations.

[4] Dadalau et al. experimentally studied the Parametric modeling of ball-screw. They emphasized in the ball-screw drives that the dynamical performance almost depends over the geometrical shape of the ballscrew. They studied the properties of ball-screw like axial and torsional stiffness, the moment of inertia, maximum velocity and acceleration, etc. To obtain these effects, the dynamic numerical (usually FEM or MBS) designs were needed.

It was concluded that by developing a parametric equation the axial and torsional stiffness of ball-screw spindles was conferred. And the analytical model along with an identified action increased the accuracy more. The model developed by the author was confirmed against the FEM model.

[5]Takafuji and Nakashima experimentally studied the stiffness of ball-screw with consideration of deformation of the screw, nut and screw thread. According to them the stiffness of the ball screw can be calculated by considering the elastic deformation of the shaft of the screw, body of thenut and threads of the screws. They also computed the axial stiffness of the ball-screws by using Hertzian contact deformation alone. The author found thestiffness of the ball-screw with the preloaded double nut. In their research, they compared experimental values with their calculated values to obtain final results. After comparing these values, they found that the calculated stiffness was lower than that of the stiffness calculated by using Hertzian contact deformation alone. 
[6] Xian-chun et al. experimentally studied axial stiffness of the Double-nut Ball-screw mechanism. They studied that by contact stress analysis and contact deformation over the high-speed double-nut some formulas can be obtained for axial stiffness of ball-screws. They analyzed that some causes affect the axial stiffness of ballscrew such as preload, helix angle, and contact angle, etc. They also analyzed the causes of these effects on the ballscrew.

It was found that there was a great effect of contact angle and preload over the axial contact stiffness of the ball-screw double-nut. And to improve the stiffness of the ball-screw the contact angle should be increased or the sufficient enlargement of preload. According to them, by enlarging the helix angle the axial rigidity of ball-screws was enhanced.

[7]Verl A. and Frey S. experimentally investigated the Correlation between Preloading and Feed velocity in Ball-Screw drive. The author studied that the preloading of ball-screw establis hes the dynamic operationalbehavior, as well as the possible life period and the value of pretension changes, depends upon feed motion velocity. They studied that this link between feed velocity and preloading has a greater impact on the actual equivalent load over ballscrew during theprocess. According to the author, there was a confined relationship between feed velocity and effective preloading in ball-screws and an increase in the rotational velocity leads to a rising in the inner forces. The relationship among rotational speed and friction produced by ball-screw can be transferred onto the effective pretension insideball-screw nut and this support for a new approach when life expectation of feed drive was calculated.

[8] Wei et al. theoretically investigated the analys is of a ball-screw with a preload and lubrication. They studied theoretically the analysis of the Kinematics of single nut double-cycle ball-screw. They analyzed that variation in the preload can be realized by making an offs et $(\lambda)$ on the middle pitch of two ball tracks and the critical load. They analyzed several parameters valid and suitable for the frictional forces composed at the ball-nut contact areas. They compared mechanical efficiencies received by considering the oil lubrication with the efficiencies received by without oil lubrication. They also experimentally studied the performance of ball-screw and mechanical efficiency over the ball-screw test machine by assuming frictional coefficients, normal forces and contact angles created at the ball-screw and ball-nut is equal by neglecting the drag force produced by the ball moving in an oil lubricant. According to them, the mechanical efficiency was high at the high screw rotational speed and preloading was decreased. To improve the mechanical efficiency the preload should beless than the applied axial load.

[9] Weule. H and Golz investigated the preloadcontrol in ball-screws. They studied that preload in the ball-screw increases the frictional loss and due to this increased friction the life span of ball-screw reduced and als o caused tear and wear. For controlling preload in ballscrew they introduced a set-up in which they used a ringshaped piezoelectric translator as an actuator. In their research, they concluded that by introducing a piezoelectric translator as actuator the life of ball-screw is increased by reducing preload in ball-screw and als o friction losses were reduced.

[10]Mu studied the Dynamic analysis of ball-screw with rotating nut driven. He studied that among the static and operation phases for the high-speed ball-screw with rotating nut there was some difference of some degrees. He studied that a dynamic design of a preload-adjustable ballscrew along with rotating nut through lumped parameters was effective for analysis of unsteady table situation and work-piece mass on the first three axial modes of uncontrolled vibrations. He used the example of a doublenut driven ball-screw pair to construct the dynamic design for double-nut ball-screw pair with modifiable preload. He also used the mass concentrated method and Lagrange equation to fabricate the dynamic design for the transmission system with a double-nut driven ball-screw pair under the venture of preload. He analyzed that at less speed the dynamics of the feeding system remained the same as in the stable state and in more speed, the dynamic is different from the stable state.

[11] Cuttino et al. experimentally and analytically investigated the identification of nonlinearities in a singlenut, preload ball-screw. They analyzed the non-linear action of a single-nut, preloaded ball-screw actuator. They recognized the resource of nonlinear torque in the ballscrew and after this, they plot that torque into the nonlinear displacement response due to expiration in the shaft. They also verified experimentally by using small-angle rotation fixture (ARC) to store very low amplitude angular displacements to the screw during the calculation of induced torque and displacements. They obtained experimental results from a precision linear optimization testbed (PLOT) which was coupled with a precision ballscrew. It was found that thenonlinearities in the ball-screw generate due to rolling friction between the balls and races, owing to which torque compelled in the nut and thereafter wind up in the shaft. According to them by using parameterized spin/torque established for a single connection region the nonlinear torque was plotted back to the ball-screw rooted over the relative spin of every loaded ball at a given spot.

[12] Shin et al. experimentally studied the Diagnosis of Ball Screw Preload Loss by Vibration Signals through the Hilbert-Huang Transformand Multi-scale Measure. They predesigned and manufactured a ball-screw with maximum preload $2 \%$ and $4 \%$ and performed their experimental study over ball-screw. They calibrated the vibration signal sample and revealed it by empirical mode decomposition (EMD) with the Hilbert spectrum. They extracted different preload characteristics and distinguished themby using HHT. It was concluded that by using HHT and MSE methods the preload loss in ball-s crew can befound. They found a computational measure of MSE (Multi-scale entropy) was used to admeasure the ball-screw dynamical subtlety and also to recognize the abnormal growth of preload loss with temperature rise. They also found that the preload loss in the ball-screw can be foreseen by the introduced methodology.

[13]Wei and Lai experimentally studied Kinematical analyses and transmission efficiency of a preloaded ball screw operating at high rotational speeds. They studied that due to high rotational speed more than 1000rpm was the reas on behind the slip-motion in the balls and raceways as 
compared to the ball-screw rotating at low speed, and due to an increase in the slip-motion the friction at contact area increases. They presented in their study a theoretical analys is of the kinematic of a preloaded single-nut, doublecycle ball-screw which is operating at high rotational speeds. They confirmed experimentally that the mechanical efficiency received from the theoretical driving torque, axial load and the orbital angular speeds of the balls. They also studied that by raising the initial contact angle the gap among the pure-rolling point and contact center can be decreased and also decreases the driving torque, especially when the operating axial load approaches the applicable preload.

According to themthe time interval and FFT methods were used to achieve the revolution speeds of balls from vibration signals computed near the returning tube of a nut. They also verified themechanical efficiency received from their introduced model. They als o found that to reduce the slip-motion the distance between the pure-rolling points and contact centers should be decreased.

[14] Tsai et al. experimentally investigated preload loss detection using ball pass frequency of ball screw. They introduced a technique to establish a preload loss in the ball-screw feed drive systemby analyzing the variation of ball-pass frequency. They studied that ball-frequency of a ball-screw preload was less as compared to ball-screw without preloaddue to friction caused by preload in ballscrew. They performed various tests over a ball-screw feed drive system with various preloads for the performance evaluation to find out the ball-pass frequency. They experimentally concluded that the ball-pass frequency can be found by using the method of Angular velocity voldkalman filtering order tracking (AV VKF-OT) which supplies too superior performance as compared to the traditional order tracking terms of motion and precision. It was found that the benefits of using AV VKF-OT to find out the BPO in the ball-screw feed drive system were that vibration which caused due to sources other than that at ball-pass frequency can be excluded in the dimensions.

\section{MATERIAL AND METHOD}

Experimentation of determining the optimal diameter of ball-screw initiates with the calculation of static load acting on ball screw using mathematical relations. The shear stress is taken as one-third of theultimate strength of the material of the ball screw. The Material for ball Screw is taken as High Carbon Steel. The table below shows the properties of High carbon steel used in this research work.

TABLE I.PROPERTIES OF THE BALL SCREW MATERIAL

\begin{tabular}{|l|l|}
\hline Material & High carbon steel \\
\hline Density & $7861.093 \mathrm{~kg} / \mathrm{m}^{3}$ \\
\hline Young's modulus (E) & $0.27-0.30 \mathrm{GPa}$ \\
\hline Poisson's Ratio & $0.27-0.30$ \\
\hline Ultimate tensile strength & $635 \mathrm{MPa}$ \\
\hline
\end{tabular}

The static load can apply an excessive force over the screw and nut during the non-moving state of the screw. If this static load rating of a distinct ball-screw assembly is surpassed. Then a permanent deflection among the screw and the steel balls of the nut occurs and due to this deflection, the system does not operate smoothly or fail. For the proper life, the static loading should never be close to the external forces. The repetition of forces debilitates the element. Some forces in static loads are hard to verify and these forces could come from vibrations, impacts and inertial forces. Therefore a factor of safety should be recognized to enumerate these forces. Formulas used to calculate the diameter of ball-screw when the condition is static Ts/Ips $=\tau s / r s$ (Torsion Equation)

$$
\begin{aligned}
& \text { Where, } \\
& T s=\text { Torque at static condition } \\
& \text { Ts }=\text { fs } \times \text { rs } \\
& I p s=\text { Polar moment of inertia at static condition } \\
& \text { Ips }=(\pi / 32) d s^{4} \\
& \tau s=\text { Maximum shear stress at static condition } \\
& r s=\text { Radius of a static condition } \\
& \text { and } \mathrm{d}_{s}{ }^{4}=\left(2 \mathrm{r}_{\mathrm{s}}\right)^{4}
\end{aligned}
$$

The dynamic load can apply a force over the nut and screw when the screw is in motion. There is a subsequent decrement in the travel life if the rated load of a distinct ball-screw assembly is surpassed. The safety factor is very important for these ratings. The safety factor helps to calculate the loads which reduce the life of the screw. When the ball screw-driven system moves there are generally resultant vibrations and impact load. The rate at which the nut of ball screw starts moving a load can influence the overall life of the ball-screw as sembly. These loads cannot be determined accurately. Therefore a safety factor is applied to determine these loads which disable the system before failure. The safety factor also helps to remunerate for changing loads, speed changing, changing acceleration rates, and also lack of lubrication. After calculating the Diameter of Ball Screw against Static Load and dynamic load the model of ball-screw is prepared with the help of design software. The ball-screw model is prepared for the diameter $14 \mathrm{~mm}$, the least diameter available in the Manual.

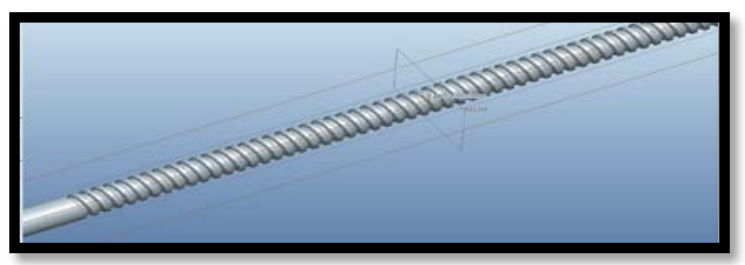

Fig. 2. Ball-screw model in the design software

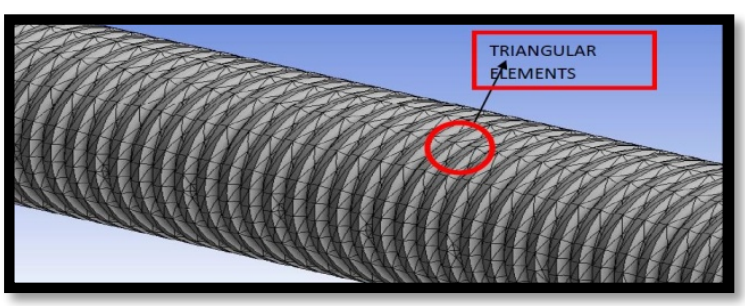

Fig. 3. Ball-screw mesh generated in analysis software

Deformation in the ball-screw is obtained as shown in Figure 5 . The values of stresses are compared with the value of ultimate tensile strength which is $635 \mathrm{MPa}$ and it 
was found that the value of stress obtained is very high. And the value of deformation is also high.So iterations for various higher diameters are carried out, which is discussed in table II.

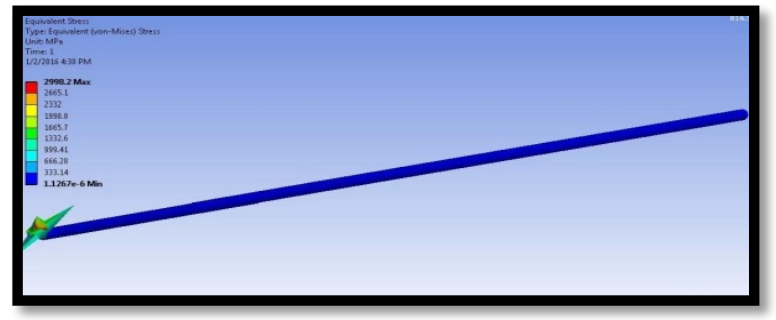

Fig. 4. Equivalent stress in $14 \mathrm{~mm}$ diameter ball screw (first iteration)

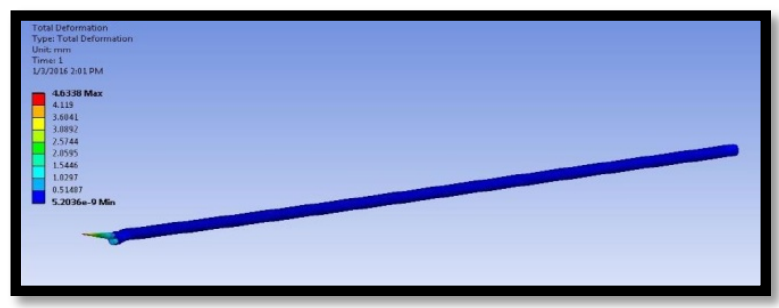

Fig. 5. Deformation respective to stress consideration in $14 \mathrm{~mm}$ diameter ball screw(First iteration)

Similarly, the iterations for various diameters of ball screw are carried out and the result obtained is shown in table below even though the value of stress was dropped to very less value when diameter was $16 \mathrm{~mm}$ but deformation was still high, and for achieving high tolerance iteration was carried out further till it reached below $5 \mathrm{~mm}$. (Value is still high but extra diameter will cause an increase in stiffness and cost so to achieve deformation below $1 \mathrm{~mm}$ another method has to applied i.e. change in the material of ball screw, supporting methods, etc.)

T ABLE II:VALUE OF STRESS AND DEFLECTION AGAINST THE BALL SCREW DIAMETERS

\begin{tabular}{|l|l|l|}
\hline Stress (MPa) & Diameter (mm) & Deflection (mm) \\
\hline 2998.2 & 14 & 60.662 \\
\hline 547.64 & 20 & 14.684 \\
\hline 700.22 & 25 & 21.701 \\
\hline 376.35 & 28 & 18.1 \\
\hline 208.43 & 32 & 12.961 \\
\hline 99.091 & 36 & 5.661 \\
\hline 62.892 & 40 & 4.6338 \\
\hline
\end{tabular}

The figure below shows the graph of variations in deflections of ball-screw at various diameters. The maximum deflection is obtained when the ball-screw diameter is $14 \mathrm{~mm}$ and the minimum deflection when the diameter is $40 \mathrm{~mm}$ as shown above.

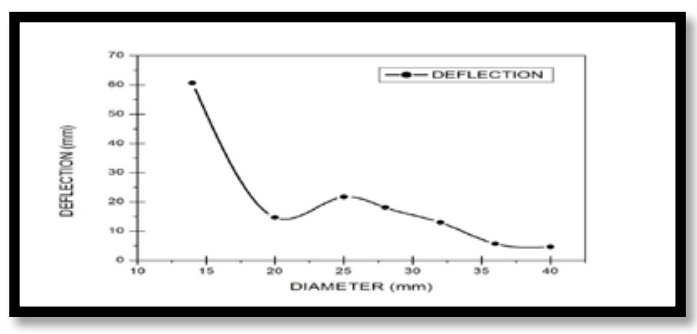

Fig. 6. Deflection, Diameter graph.
The figure below shows the graph of variations in the stress of the ball-screw at various diameters. The maximum stress is obtained when the ball-screw diameter is $12 \mathrm{~mm}$ and the minimum stress when the diameter is $40 \mathrm{~mm}$. as shown above. Both graphs show the lowering in the value of stress and deflection with an increase in diameter with small variation, which is an obvious fact with the increase in cross-sectional area.The change was found rapid with a change in diameter from $14 \mathrm{~mm}$ to 16 $\mathrm{mm}$ after that there was little change in the behavior of stress and deflection.It means that although $16 \mathrm{~mm}$ diameter is safe but to achieve high cutting tolerance the diameter has to be changed.

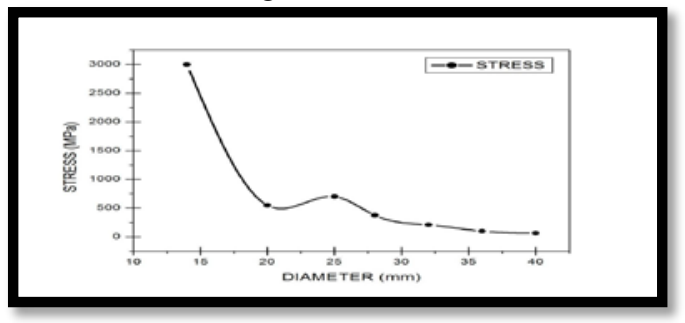

Fig. 7. Stress, Diameter graph.

\section{CONCLUSION}

- From the various iterations, it has been found that the diameter found out for the ball screw is being safe for use.

- The experimental results have been successfully validated with FEM modal and the design is safe to use.

- After various optimizations, it has been found that at $40 \mathrm{~mm}$ diameter of the shaft the tool deflection was $4.6338 \mathrm{~mm}$ which is minimum and subsequently stress occurred was $62.892 \mathrm{MPa}$

- To further reduce deflection it is better to use another material for manufacturing ball screw rather than increasing weight further any more as this will lead to excessive weight and cost.

\section{REFERENCES}

[1]. http://www.dynatect.com/mechanical-motioncontrol/ball-screw/ball-screw-design-guide/diagrams

[2]. M. F.Zaeh, Th. Oertli, and J. Milberg, "Finite element modelling of ball screw feed drive systems," CIRP Annals-Manufacturing T echnology, vol. 53(1),pp.289292, 2004.

[3]. Kamalzadeh, Amin, J.Daniel Gordon and Kaan Erkorkmaz, "Robust compensation of elastic deformations in ball screw drives," International Journal of Machine Tools and Manufacture, vol.50 (6), pp.559-574, 2010.

[4]. D. Alexandru et al. "Parametric modeling of ball screw spindles,” Production Engineering, vol.4 (6), 625-631, 2010.

[5]. T. Kazuki and K. Nakashima, "Stiffness of a ball screw with consideration of deformation of the screw, net and screw thread Preloaded double nut," JSME international journal. Ser. 3, Vibration, control engineering, engineering for industry, vol. 33.4,pp.620$626,1990$.

[6]. X. C. Song et al. "Research on Axial Stiffness of the Double-nut Ball Screw Mechanism,” Proceedings of the 1st International Conference on Mechanical Engineering and Material Science, Atlantis Press, 2012. 
[7]. A.Verl, and S. Frey, "Correlation between feed velocity and preloading in ball screw drives," CIRP AnnalsManufacturing Technology,vol. 59.1,pp.429-432.2010.

[8]. W.C. Chung, J.F. Lin, and J.H.Horng, "Analysis of a ball screw with a preload and lubrication, "Tribology International 42.11,pp.1816-1831.2009.

[9]. H.Weule and H. U. Golz, "Preload-Control in Ball Screws-A New Approach for Machine Tool Building, “CIRP Annals-Manufacturing Technology, vol. 40.1, pp.383-386,1991.

[10].S. Mu, "Dynamic Analysis of Ball-Screw with Rotating Nut Driven,” Computer Modelling \& New Technologies, vol.18 (4), pp. 268-272, 2014.

[11].J. F. Cuttino, T.A. Dow, and B.F. Knight, “Analytical and experimental identification of nonlinearities in a single-nut, preloaded ball screw,”Journal of Mechanical Design, vol.119.1, pp.15-19, 1997.

[12].S.Y. Chen, Y.C. Huang, and J.A. Chao, "Diagnosis of Ball Screw Preload Loss by Vibration Signals through the Hilbert-Huang Transform and Multiscale Measure," Applied Mechanics and Materials, Vol. 58, 2011.

[13].W. Chin-Chung and R.S. Lai, "Kinematical analyses and transmission efficiency of a preloaded ball screw operating at high rotational speeds," Mechanism and machine Theory, vol. 46.7, pp.880-898, 2011.

[14].P.C.Tsai, C.C. Cheng, and Y.C. Hwang, "Ball screw preload loss detection using ball pass frequency," Mechanical Systems and Signal Processing, vol. 48.1, pp.77-91, 2014. 